\title{
COURTSHIP BEHAVIOR IN THE ALPINE NEWT TRITURUS ALPESTRIS AT TWO DIFFERENT DENSITIES OF MALES
}

\author{
Mathieu Denoël ${ }^{1}$, Marie-Pierre Hector, and Pascal Poncin \\ Laboratory of Fish and Amphibian Ethology, Behavioural Biology Unit, \\ Department of Environmental Sciences, University of Liège, \\ Quai Van Beneden 22, 4020 Liège, Belgium
}

\begin{abstract}
Aвstract: The aim of this laboratory experiment was to examine courtship behavior and reproductive success under two different perceived male densities in the Alpine newt (Triturus alpestris). Male behavioral patterns were similar at unbiased and male-biased operational sex ratios (OSR). Although the exhibition of luring behaviors is risky in the presence of other males, no difference in the frequencies of displays was found at the two male densities. Similarly, the responsiveness of females towards males and the success rate of the encounters (i.e., spermatophore transfer) were not explained by the OSR. Our results show that courting Alpine newts do not change their courtship patterns when other males are present and do not interact directly. However they are not necessarily opposed to those of previous experiments showing sexual interference and female aversion in male-biased OSR with possibility of interactions. These observations suggest that the evolution of courtship behavior may not be driven by the risk of sexual interference with other males prior to potential physical contact and that the benefits of breeding regardless of OSR can overcome the risk of competition at male-biased OSR.
\end{abstract}

Key words: Alternative mating tactics; Density; Newts; Operational sex ratio; Sexual defense; Sexual selection

The operational sex ratio (OSR) is the average ratio of fertilizable females to sexually active males at any given time (Emlen and Oring, 1977). Sexual selection theories predict that OSR plays a fundamental role in shaping behavioral patterns and mate choice (Kvarnemo and Ahnesjö, 1996, 2002). OSR can be used as a tool to determine the intensity of competition and to predict which sex should be the most competitive (Kvarnemo and Ahnesjö, 1996, 2002). The sex involved in parental care, egg production or ejaculate replenishment is usually in "time out"; this sex becomes limiting and can then afford to be choosy while the other sex may display alternative reproductive behavior to increase its success (Clutton-Brock and Parker, 1992; Trivers, 1972). Females usually are expected to be the choosy sex because males typically have a higher potential reproductive rate (CluttonBrock and Parker, 1992). However, the opposite result may occur in species with reversed sex roles (i.e., in which males may have a lower reproductive rate than females) (Kvarnemo and Ahnesjö, 1996, 2002).

Empirical data support these predictions. In male-biased OSR, males often compete more

\footnotetext{
${ }^{1}$ Correspondence: e-mail, Mathieu.Denoel@ulg.ac.be
}

intensively for mates than females (CluttonBrock and Parker, 1992; Clutton-Brock and Vincent, 1991; Thomas and Manica, 2005) and exhibit alternative mating tactics (Evans and Magurran, 1999; Kodric-Brown, 1988; Mills and Reynolds, 2003; Randall et al., 2002; Shine et al., 2003). The opposite pattern also occurs in species with female-biased OSR (Almada et al., 1995; Berglund, 1994; CluttonBrock and Parker, 1992; Clutton-Brock and Vincent, 1991; Jones et al., 2001). In such male- and female-biased OSR, the less common sex has the opportunity to become more selective without losing mating opportunities as relatively more potential mates are present (Balshine-Earn, 1996; Enders, 1993; Jirotkul, 1999; Kvarnemo and Ahnesjö, 2002). Despite these findings, some recent models suggest that OSR is not the most fundamental determinant in sex roles (Kokko and Johnstone, 2002; Kokko and Monaghan, 2001). Instead, they consider that the cost of a single breeding attempt has a strong direct effect on competition and choosiness. In these models, OSR is still a predictor of the direction of sexual selection, as biases cause sex differences in encounter rates. However, other variables, such as mortality costs and variation in mate quality, are considered to be effective (Kokko and Johnstone, 2002; Kokko and Monaghan, 2001). 
In newts and salamanders, the OSR system is usually male-biased, particularly with the advance of the reproductive season as females are occupied with laying eggs (Halliday, 1977, 1990; Verrell, 1984a; Verrell and McCabe, 1988). In such male-biased OSR, rival males may directly interfere with courting pairs in displaying to the female and in inseminating her (Arnold, 1976; Massey, 1988; Verrell, 1984c). This tactic is favored by the mode of reproduction of most of these species, i.e., by means of a spermatophore deposited in the external environment (Verrell, 1989; Denoël, 2000). In response to the risk caused by other males, sexual defense (moving with the female away from all potential competitors: Verrell, $1984 c$; maintaining the female in an amplexus: Verrell, 1983; fighting: Raxworthy, 1989) can be exhibited.

Alpine newt males also can exhibit sexual interference (Denoël, 2003a; Verrell, 1988) and possibly some kinds of sexual defense in moving away from male competitors (Verrell, 1988). However, in these experiments in which rivals were allowed to move between the focal animals, most of the sexual encounters ended at the arrival of another male (Denoël, 2003a). The effect of OSR on precontact of males has been studied in fish (e.g., Berglund, 1994), but it is not known whether male newts can use different behavioral patterns, and particularly alternative mating tactics, in the presence of rival males that cannot interact directly. It may be expected that newts have developed alternative mating tactics to prevent sexual interference not only when rivals interact, but also when they are in close proximity. In such a situation, remaining close to interfering males or using luring tactics may be risky because the courting males may lose the courted female and his investment in terms of displaying time and spermatophore production (Denoël et al., 2001a; Denoël, 2003a). The effect of OSR on pre-contact behavior of female newts also is not known because all previous experiments allowed direct contact between the courting pairs and rivals (Denoël, 2003a; Verrell, 1984c, 1988). In such experiments, females often moved away from males when other males interacted. It may thus be expected that females would also be less responsive to males in male-biased perceived OSR.
The aim of this study was to find out (1) whether alternative courtship of male newts was influenced by OSR, and (2) whether responsiveness of females differs depending on their perception of OSR, i.e., when other males are present in the environment but without interacting physically.

\section{Methods}

\section{Reproductive Behavior of Alpine Newts}

The courtship behavior of Alpine newts takes place in water. It is composed of several behaviors exhibited by the male towards the female, which either responds positively or negatively to the male. After this display phase, the male may deposit a spermatophore on the substratum and the female may pick it up (Denoël, 1996, 2000, 2003b; Halliday, 1977). Males also may exhibit alternative mating tactics: they may attract unresponsive females at the time of spermatophore transfer by using luring movements (Denoël, 2002; Denoël et al., 2001a), and they may interfere with a courting pair by displaying and inseminating the female (Denoël, 2003a; Verrell, 1988). In natural conditions, although isolated dyadic male-female encounters are frequent, the typical breeding system of the Alpine newt is male-biased with several males at the vicinity of courting pairs (Denoël, 1996; M. Denoël, personal observations).

\section{Sampling and Laboratory Maintenance}

Adult Alpine newts (80 females and 90 males) were caught at Boirs, Liège Province, Belgium $\left(50^{\circ} 45^{\prime} \mathrm{N}-5^{\circ} 36^{\prime} \mathrm{E}, 70 \mathrm{~m}\right.$ elevation a.s.l.) on a road during their migration from their hibernation place to their reproductive pond. Collection took place at the start of the breeding period, i.e., at the end of February and in early March 2001. Because newts were caught before their entrance into the pond, they had not yet reproduced that year. All newts that were caught were mature individuals (swollen cloacae in males; grooved cloacae in females: Denoël et al., 2001b). The specimens were carried directly to the laboratory (20 min drive) after their capture. Males and females were kept separately in seven aquaria ( $3 \mathrm{~m}^{3}$ total water volume). The newts were fed four times a week with Chironomus larvae. 
Mean water temperature was $13 \mathrm{C}$ and photoperiod was $14 \mathrm{~h}$ light/10 h dark, i.e., conditions experienced by newts during the reproductive season. All newts were released in their native habitat after completion of the experiment.

\section{Experimental Procedures}

Dyadic encounters $(n=80)$ were staged in the month after the capture date, i.e., within the normal breeding period of the species (Denoël, 1996). All encounters were independent as each individual was used only once. They took place with males and females that had not yet been involved in sexual interactions. The experiment was conducted in an aquarium measuring $60 \times 30 \times 30 \mathrm{~cm}$ and containing a gravel substrate (water depth: $25 \mathrm{~cm}$ ). A grid placed at $5 \mathrm{~cm}$ from one of the lateral walls reduced the length of the aquarium to $55 \mathrm{~cm}$. Half of the trials were conducted with the grid placed on the left side, the other half, with the grid on the right side. Two metallic rulers placed on the substrate allowed the determination of the position of the newts in the aquarium. The water temperature was kept at mean $\pm \mathrm{SD}=12.5 \pm 0.5$ $\mathrm{C}$ and the light intensity was 5000 lux at the bottom of the aquarium. The tank tape water was replaced after each trial. Encounters were staged in the morning and recorded with a Sony digital 8 camcorder (TRV-510).

Reproductive encounters were staged using two treatments: an unbiased OSR and a malebiased OSR. In the male-biased OSR, two adult males were placed in the small compartment behind the grid. In the unbiased OSR, the space behind the grid was left empty (unbiased sex ratio). Males (unbiased: mean \pm $\mathrm{SE}=51.9 \pm 0.4 \mathrm{~mm}$; male-biased: $51.3 \pm 0.4$ $\left.\mathrm{mm} ; t_{78}=1.295, P=0.20\right)$ and females (unbiased: $59.4 \pm 0.6 \mathrm{~mm}$; male-biased: $58.2 \pm 0.5 \mathrm{~mm} ; t_{70}=1.592, P=0.12$ ) used in the two treatments did not differ in snoutvent length. One hour after introducing the two males in the small compartment, one male and one female were introduced in the large compartment. One trial with male-biased sex ratio was followed by one trial with unbiased sex ratio, and so on. The recorded behavioral patterns are those from the pair in the large compartment. The two males in the small compartment could not interact directly with the courting pair because of the grid, but both visual and chemical communications were possible given the large mesh of the grid (squares of $6 \times 6 \mathrm{~mm}$ ) and the thinness of the grid itself $(0.5 \mathrm{~mm})$. Indeed, in natural ponds, newts can perceive conspecifics up to at least one meter and can find individuals partly hidden in heterogeneous habitats (M. Denoël, personal observations), so we believe that the caged newts should have been perceived by the focal newts. Moreover, we observed that focal newts were able to move in straight line towards both their potential partners and caged individuals. Observations were conducted until the end of the sexual activities between the two partners (i.e., when at least one min elapsed without courting behavior). The trial also was stopped if the male swam to the water surface because the probability of the male finding the female again in natural conditions is considered to be low after this event (Halliday, 1977).

Videotapes were then screened and all male behaviors were encoded on a computer (for the full list of behaviors, see Denoël 2003b). Sequencing and timing (in s) were obtained using software developed in our laboratory which allowed us to record behavior in real time. Subsequent viewing of the tapes made it possible to note the behavior of the female in response to each behavior of the males. We focused on the key behavioral patterns of the encounters by taking into account time and count data. We characterize the different behaviors by using duration, index, binary and distance parameters (see Table 1 for the list and description).

\section{Statistical Procedures}

Dependent variables were analyzed with multivariate analyses of variance (MANOVA) and univariate tests (ANOVA and student $t$-tests), with alpha set at 0.05 . As response index of females affects behavior of males (Denoël, 2002; Denoël et al., 2001a, 2005; this study), this trait was used as covariate in MANCOVA analyses to control it in testing for an effect of OSR. To achieve normality, proportions were transformed by arcsine, other continuous data by log transformation, and counts by square-root +0.5 transformation 
TABLE 1.-List and description of the analysed behavioral patterns.

\begin{tabular}{|c|c|}
\hline Behavioral pattern & Description \\
\hline \multicolumn{2}{|l|}{ Duration parameters } \\
\hline Display latency of males & $\begin{array}{l}\text { The time from the pair entering the aquarium to the first display (i.e., the } \\
\text { fanning movement) of the male to the female }\end{array}$ \\
\hline Transfer latency & The time from the first display to the first spermatophore deposition \\
\hline \multicolumn{2}{|l|}{ Index parameters } \\
\hline Fanning index & $\begin{array}{l}\text { The proportion of time in fanning posture (i.e., during which males may } \\
\text { exhibit the fanning display, make no movement [static fan] or slowly } \\
\text { move the tip of the tail [wiggle-tail-bent]) during which the male } \\
\text { exhibited the fan (only encounters with at least } 10 \text { bouts of any } \\
\text { courtship behavior were considered; the fan is the most used courtship } \\
\text { display in the Alpine newt) }\end{array}$ \\
\hline Display index & $\begin{array}{l}\text { The proportion of time during which the male exhibited display (display } \\
\text { and transfer included) }\end{array}$ \\
\hline Foreplay index & $\begin{array}{l}\text { The proportion of time (in display and transfer phases) during which the } \\
\text { male exhibited display to the time spent }\end{array}$ \\
\hline Female positive response index & $\begin{array}{l}\text { The proportion of time during which the female was responsive to the } \\
\text { male (i.e., moving toward the male or turning her head toward his head } \\
\text { or tail) }\end{array}$ \\
\hline \multicolumn{2}{|l|}{ Binary and count parameters } \\
\hline Display & $\begin{array}{l}\text { The proportion of all encounters during which courtship behaviors was } \\
\text { exhibited }\end{array}$ \\
\hline Encounter success & $\begin{array}{l}\text { It is successful when at least one spermatophore was transferred from the } \\
\text { male to the female }\end{array}$ \\
\hline Spermatophore deposition & The number of spermatophores deposited during an encounter \\
\hline Creep with unresponsive female & $\begin{array}{l}\text { The proportion of spermatophore transfer phases initiated without } \\
\text { a positive response from the female (i.e., exhibition of the behavior } \\
\text { "creep") }\end{array}$ \\
\hline $\begin{array}{l}\text { Spermatophore deposition with } \\
\text { unresponsive female }\end{array}$ & $\begin{array}{l}\text { The proportion of spermatophore deposition events without the female's } \\
\text { tail touch (a stimulus eliciting spermatophore deposition) }\end{array}$ \\
\hline Quiver & $\begin{array}{l}\text { The proportion of encounters with the luring behavioral pattern "quiver" } \\
\text { (quivering of tail in the same axis as the body at the start of } \\
\text { spermatophore transfer phase) }\end{array}$ \\
\hline Distal lure & $\begin{array}{l}\text { The proportion of encounters with the luring behavioral pattern "distal } \\
\text { lure" (slow and wide motion of the tip of the tail after spermatophore } \\
\text { deposition; only encounters with spermatophore transfer phase were } \\
\text { considered) }\end{array}$ \\
\hline \multicolumn{2}{|l|}{ Distance parameter } \\
\hline Mean distance to the grid & $\begin{array}{l}\text { To determine the position of the newts to the grid, the mean time spent in } \\
\text { the three different parts of the observation aquarium was calculated } \\
\text { This value was obtained by multiplying the distance }(\mathrm{cm}) \text { from the central } \\
\text { point of each of the three equal areas (on the floor of the observation } \\
\text { aquarium) to the grid (i.e., } 9,27 \text { and } 45 \mathrm{~cm} \text { ) by the time spent in each } \\
\text { area, and dividing that by the duration of the encounter }\end{array}$ \\
\hline
\end{tabular}

before we calculated the parametric significance tests. Chi-square tests were computed to compare proportions of events in $2 \times 2$ contingency tables (Sokal and Rohlf, 1995).

\section{RESUlts}

Most of the 80 encounters (89\%) included courtship behavior of the male towards the female. The proportion of encounters that included sexual display by males, did not differ between unbiased and male-biased OSR
(Operational Sex Ratio) treatments (85\% vs. $93 \%$ respectively, $n=40$ in each; $\chi^{2}=1.13$, $\mathrm{df}=1, P=0.29)$.

In encounters involving sexual behavior, display and transfer latencies as well as foreplay, display time and fanning indexes, mean distance to the grid and spermatophore deposition were not significantly affected by OSR (MANOVA: $\lambda=0.811, F_{7,32}=0.811, P=$ 0.59; Table 2). Positive response index of females had a significant effect on behavioral 
patterns of males (MANCOVA: $\lambda=0.292$, $\left.F_{7,31}=10.749, P<0.001\right)$, but effect of OSR was not significant (MANCOVA: $\lambda=0.879$, $F_{7,31}=0.611, P=0.74$ ). Positive response index of females significantly affected transfer latency $\left(F_{1,38}=11.816, P<0.01\right)$, foreplay index $\left(F_{1,38}=27.951, P<0.001\right)$, and the number of spermatopores deposited $\left(F_{1,38}=\right.$ 9.525, $P<0.01)$. Shorter transfer latencies, larger foreplay indexes and more spermatophore depositions were exhibited with highly responsive females.

Male Alpine newts started the spermatophore transfer phase (i.e., crept ahead of the female after the display phase) with both responsive and unresponsive females. The proportion of encounters in which males initiated spermatophore transfer phase without a positive response from the female did not differ between unbiased $(43 \%, n=28)$ and malebiased OSR $(38 \%, n=24)$ treatments $\left(\chi^{2}\right.$ test $=0.15,1 \mathrm{df}, P=0.70)$. After initiation of the spermatophore transfer phase, some males deposited spermatophores while other males did not deposit any spermatophores in front of unresponsive females, i.e., females that did not touch their tail. No significant effect of OSR was found on spermatophore deposition to unresponsive females (unbiased OSR: $32 \%, n=24$, male-biased OSR: $38 \%, n=24$, $\chi^{2}$ test $\left.=0.16,1 \mathrm{df}, P=0.69\right)$. During the spermatophore transfer phase, males used luring tactics, i.e., the exhibition of acts which are mainly exhibited in front of unresponsive females to increase female responsiveness. These acts were the quiver and the distal lure. However, males from the two OSR treatments did not differ in the exhibition of these behavioral patterns (Quiver, unbiased OSR: $39 \%, n=28$, male-biased OSR: $29 \%, n=24$, $\chi^{2}$ test $=0.58,1 \mathrm{df}, P=0.45$; Distal lure, unbiased OSR: $39 \%, n=28$, male-biased OSR: $42 \%, n=24, \chi^{2}$ test $=0.03,1 \mathrm{df}, P=0.86$ ).

Insemination success was defined as occurring when females picked up the spermatophore. Insemination success rates did not differ between unbiased and male-biased OSR treatments $(20 \%$ vs. $23 \%$ respectively, $n=40$ in each; $\left.\chi^{2}=0.07,1 \mathrm{df}, P=0.78\right)$. Positive response indexes of females were not significantly affected by OSR $\left(t_{64}=\right.$ 0.098, $P=0.92): 35 \pm 8 \%$ in unbiased OSR, and $30 \pm 6 \%$ in male-biased OSR.
TABLE 2.-Courtship activity (mean $\pm \mathrm{SE}$ ) of focal male Alpine newts in unbiased and male-biased operational sex ratio (OSR) treatments. MANOVA: $\lambda=0.811$, $F_{7,32}=0.811, P=0.59$. See Table 1 for the description of patterns.

\begin{tabular}{lcrcc}
\hline \multicolumn{1}{c}{$\begin{array}{c}\text { Behavioral } \\
\text { pattern }\end{array}$} & $\begin{array}{c}\text { Unbiased } \\
\text { OSR }(n=19)\end{array}$ & $\begin{array}{c}\text { Male-Biased } \\
\text { OSR }(n=21)\end{array}$ & $F$ & $P$ \\
\hline Display latency & $521 \pm 103 \mathrm{~s}$ & $511 \pm 81 \mathrm{~s}$ & 0.196 & 0.66 \\
Transfer latency & $259 \pm 50 \mathrm{~s}$ & $259 \pm 61 \mathrm{~s}$ & 0.373 & 0.55 \\
Fanning index & $61 \pm 3 \%$ & $58 \pm 4 \%$ & 0.446 & 0.51 \\
Foreplay index & $54 \pm 5 \%$ & $46 \pm 6 \%$ & 0.978 & 0.33 \\
$\begin{array}{l}\text { Display index } \\
\text { Spermatophore } \\
\text { deposition }\end{array}$ & $92 \pm 1 \%$ & $89 \pm 2 \%$ & 1.206 & 0.28 \\
$\begin{array}{c}\text { Mean distance } \\
\text { to the grid }\end{array}$ & $28 \pm 0.3$ & $2.5 \pm 0.2$ & 0.172 & 0.68 \\
\hline
\end{tabular}

\section{DisCUSSION}

The results of our experiment show that the presence of males close to a courting pair, without direct interaction, did not affect the courtship and responsiveness of the Alpine newt. This is in contrast to expectations from other empirical studies with other species (Evans and Magurran, 1999; Jirotkul, 1999; Kodric-Brown, 1988; Mills and Reynolds, 2003; Randall et al., 2002) and thus in apparent opposition with the classical predictions that OSR plays a primary role in shaping behavioral patterns (Emlen and Oring, 1977; Kvarnemo and Ahnesjö, 1996, 2002). In the Alpine newt, courting males exhibited the same behavioral patterns in unbiased OSR as under a perceived excess of males. This result supports the recent view that OSR alone does not determine the direction of sexual selection (Kokko and Johnstone, 2002; Kokko and Monaghan, 2001). Cost:benefit ratios of mating versus nonmating are then expected to be more important than OSR in shaping behavioral patterns of newts. That does not mean that newts do not exhibit alternative mating tactics in the presence of conspecifics, as such patterns are known in other species of newt (Raxworthy, 1989; Verrell, 1983, 1984c), including the Alpine newt (Denoël, 2003a; Verrell, 1988). Our data show that, when a pair of newts is involved in courtship display, they do not react to other males as long as they do not move towards them, a pattern which has not been studied until now in any species of newts.

The two levels of male densities of this experiment occur in natural populations of Alpine newts (Denoël, 1996), and the presence 
of interfering males is even considered to be more the rule than the exception in newts as the reproductive rate of males is higher than that of females (Halliday, 1990; Verrell, $1984 b)$. In natural populations of Alpine newts, males display to females both when no other males are present and when several males are in the vicinity. Density and operational sex ratio are confounded in our experimental framework because the effect of caged females was not tested in this study. Future research might focus on this topic. Nevertheless, this difference is irrelevant in the present case because no significant effect was observed.

In male-biased OSR, the exhibition of some alternative mating tactics, such as the use of luring displays, is believed to be risky (Denoël et al., 2001a; Denoël, 2002). Indeed, while the courting male is using these displays, he loses his female from sight during a short period (initiation of spermatophore transfer) and displays at longer distances than usual, which may facilitate sexual interference by rival males (Denoël et al., 2001a; Denoël, 2002). This is particularly risky because spermatophores are a limiting resource and because the success of luring is low even in the absence of rivals (Denoël et al., 2001a). However, this study shows that males use the luring behavioral patterns and start spermatophore transfer at the same frequencies regardless of OSR. Males thus choose the option of the direct potential mating benefit in trying to inseminate females even if competitors are present.

Previous experiments showed that females moved away from the courting male when other individuals could directly interfere (Denoël, 2003a; Verrell, 1984b, 1988). The success of encounters was thus affected in male-biased OSR. In this study, the responsiveness of females toward males was similar in unbiased and male-biased OSR. This similarity indicates that, like males, females did not show aversion to the presence of other individuals as long as rival males did not directly interfere.

In conclusion, this study shows that Alpine newts have not developed major behavioral adaptations in their courtship behavior to different perceived densities or changing OSR. The high availability of mates, even in biased OSR, along with the high potential of multiple mating for both males and females (Rafinski and Osikowski, 2002; Verrell, 1988), makes the absence of alternative tactics not necessarily costly. This can be seen as a sidepayment strategy (Dunbar, 1982) as Alpine newts may capitalize on small gains in taking benefit from each passing opportunity whatever the risk of interference with competing newts or reproduction with lower quality mates. In garter snakes, males find also good advantages in reproducing at male-biased sex ratio because they need to stimulate less the female than when they are isolated (Shine et al., 2003). The breeding advantage of mating may then have a greater role than OSR in the Alpine newt and is thus in agreement with the view that OSR is not necessarily the primary selective factor shaping courtship tactics (Kokko and Johnstone, 2002; Kokko and Monaghan, 2001).

Acknowledgments.-We thank M. Jaroensutasinee, L. Kvarnemo, A. Mathis, P. H. Niewiarowski, M. Seymour and two anonymous reviewers for their valuable comments on the manuscript. A collecting permit was provided by the Ministère de la Région Wallonne. This study benefited from FNRS grants 1.5.011.03 and 1.5.120.04 (Crédit aux chercheurs). Mathieu Denoël is post-doctoral researcher at the Fonds National de la Recherche Scientifique (F.N.R.S.).

\section{Literature Cited}

Almada, V. C., E. J. Gonçalves, R. F. Oliveira, and A. J. SANTOS. 1995. Courting females: ecological constraints affect sex roles in a natural population of the bleniid fish Salaria pavo. Animal Behaviour 49:1125-1127.

ARnold, S. J. 1976. Sexual behavior, sexual interference and sexual defense in the salamanders Ambystoma maculatum, Ambystoma tigrinum and Plethodon jordani. Zeitschrift für Tierpsychologie 42:247-300.

Balshine-Earn, S. 1996. Reproductive rates, operational sex ratios and mate choice in St. Peter's fish. Behavioral Ecolology and Sociobiology 39:107-116.

Berglund, A. 1994. The operational sex ratio influences choosiness in a pipefish. Behavioral Ecology 5: 254-258.

Clutton-Brock, T. H., and G. A. Parker. 1992. Potential reproductive rates and the operation of sexual selection. Quarterly Review of Biology 67:437-456.

Clutton-Brock, T. H., and A. C. J. Vincent. 1991. Sexual selection and the potential reproductive rates of males and females. Nature 351:58-60.

DenoëL, M. 1996. Etude comparée du comportement de cour de Triturus alpestris alpestris (Laurenti, 1768) et Triturus alpestris cyreni (Wolterstorff, 1932) (Amphibia, Caudata): approche évolutive. Cahiers d'Ethologie 16:133-258.

2000. Le comportement social des urodèles. Cahiers d'Ethologie 19:221-258.

2. 2002. Paedomorphosis in the Alpine newt (Triturus alpestris): decoupling behavioural and morphological change. Behavioral Ecology and Sociobiology 52:394-399. 
2003a. Effect of rival males on the courtship of paedomorphic and metamorphic Triturus alpestris. Copeia 2003:618-623.

2003b. Avantages sélectifs d'un phénotype hétérochronique. Eco-éthologie des populations pédomorphiques du Triton alpestre, Triturus alpestris (Amphibia, Caudata). Cahiers d'Ethologie 21:1-327.

Denoël, M., P. Poncin, And J. C. Ruwet. 2001a. Alternative mating tactics in the Alpine newt Triturus alpestris alpestris. Journal of Herpetology 35:62-67.

. 2001b. Sexual compatibility between two heterochronic morphs in the Alpine newt, Triturus alpestris. Animal Behaviour 62:559-566.

Denoël, M., M. Mathieu, and P. Poncin. 2005. Effect of water temperature on the courtship behavior of the Alpine newt Triturus alpestris. Behavioral Ecology and Sociobiology 58:121-127.

Dunbar, R. I. M. 1982. Intraspecific variations in mating strategy. Pp. 385-431. In P. P. G. Bateson and P. H. Klopfer (Eds.), Perspectives in Ethology. Plenum Press, New York, New York, U.S.A.

Emlen, S. T., and L. W. Oring. 1977. Ecology, sexual selection, and the evolution of mating systems. Science 197:215-223.

Enders, M. M. 1993. The effect of male size and operational sex ratio on male mating success in the common spider mite, Tetranychus urticae (Acari: Tetranychidae). Animal Behaviour 46:835-846.

Evans, J. P., and A. E. Magurran. 1999. Male mating behaviour and sperm production characteristics under varying sperm competition risk in guppies. Animal Behaviour 58:1001-1006.

HaLliday, T. 1977. The courtship of European newts: an evolutionary perspective. Pp. 185-232. In D. H. Taylor and S. I. Guttman (Eds.), The Reproductive Biology of Amphibians. Plenum Press, New York, New York, U.S.A. . 1990. The evolution of courtship behavior in newts and salamanders. Advances in the Study of Behavior 19:137-169.

JiвоткuL, M. 1999. Operational sex ratio influences female preference and male-male competition in guppies. Animal Behaviour 58:287-294.

Jones, A. G., D. Walker, C. Kvarnemo, K. Lindström, AND J. C. Avise. 2001. How cuckoldry can decrease the opportunity for sexual selection: Data and theory from a genetic parentage analysis of the sand goby, Pomatoschistus minutus. Proceedings of the National Academy of Sciences USA 98:9151-9156.

Kodric-Brown, A. 1988. Effects of sex-ratio manipulation on territoriality and spawning success of male pupfish, Cyprinodon pecosensis. Animal Behaviour 36: $1136-1144$

Koкko, H., And R. A. Johnstone. 2002. Why is mutual mate choice not the norm? Operational sex ratios, sex roles and the evolution of sexually dimorphic and monomorphic signalling. Philosophical Transactions of the Royal Society of London, Series B, Biological Sciences 357:319-330.

Koкko, H. P., and P. Monaghan. 2001. Predicting the direction of sexual selection. Ecology Letters 4:159-165.

Kvarnemo, C., and I. Ahnesjö. 1996. The dynamics of operational sex ratios and competition for mates. Trends in Ecology and Evolution 11:404-408.
2002. Operational sex ratios and mating competition. Pp. 366-382. In I. C. W. Hardy (Ed.), Sex Ratios: Concepts and Research Methods. Cambridge University Press, Cambridge, U.K.

Massey, A. 1988. Sexual interactions in red-spotted newt populations. Animal Behaviour 36:205-210.

Mills, S. C., And J. D. Reynolds. 2003. Operational sex ratio and alternative reproductive behaviours in the European bitterling, Rhodeus sericeus. Behavioral Ecology and Sociobiology 54:98-104.

Rafinski, J., AND A. OsikowSKi. 2002. Sperm mixing in the Alpine newt (Triturus alpestris). Canadian Journal of Zoology 80:1293-1298.

Randall, J. A., E. R. Hekkala, L. D. Cooper, and J. BARFIELD. 2002. Familiarity and flexible mating strategies of a solitary rodent, Dipodomys ingens. Animal Behaviour 64:11-21.

Raxworthy, C. J. 1989. Courtship, fighting and sexual dimorphism of the banded newt, Triturus vittatus ophryticus. Ethology 81:148-170.

Shine, R., T. Langkilde, and R. T. Mason. 2003. The opportunistic serpent: male garter snakes adjust courtship tactics to mating opportunities. Behaviour 140:1509-1526.

Sokal, R. R., And F. J. Rohlf. 1995. Biometry. Freeman and Co, New York, New York, U.S.A.

Thomas, L. K., AND A. Manica. 2005. Intrasexual competition and mate choice in assassin bugs with uniparental male and female care. Animal Behaviour 69:275-281

Trivers, R. L. 1972. Parental investment and sexual selection. Pp. 136-179. In B. Campbell (Ed.), Sexual Selection and the Descent of Man. Aldine Press, Chicago, Illinois, U.S.A.

Verrell, P. A. 1983. The influence of the ambient sex ratio and intermale competition on the sexual behavior of the red-spotted newt, Notophthalmus viridescens (Amphibia: Urodela: Salamandridae). Behavioral Ecology and Sociobiology 13:307-313.

- 1984a. The responses of inseminated female smooth newts, Triturus vulgaris, to further exposure to males. British Journal of Herpetology 6:414-415.

. 1984b. Responses to different densities of males in the smooth newt, Triturus vulgaris. "One at a time, please”. Journal of Herpetology 18:482-484.

. 1984c. Sexual interference and sexual defense in the smooth newt, Triturus vulgaris (Amphibia, Urodela, Salamandridae). Zeitschrift für Tierpsychologie 66: 242-254.

. 1988. Sexual Interference in the Alpine newt, Triturus alpestris (Amphibia, Urodela, Salamandridae). Zoological Sciences 5:159-164.

1989. The sexual strategies of natural populations of newts and salamanders. Herpetologica 45: 265-282.

Verrell, P., and N. McCabe. 1988. Field observations of the sexual behavior of the smooth newt, Triturus vulgaris vulgaris (Amphibia, Salamandridae). Journal of Zoology, London 214:533-545.

Accepted: 2 August 2005

Associate Editor: Peter H. Niewiarowski 